\title{
What Effects Does Necrotic Area of Contrast-Enhanced MRI in Osteoporotic Vertebral Fracture Have on Further Compression and Clinical Outcome?
}

\author{
Ja Myoung Lee, M.D., ${ }^{1}$ Young Seok Lee, M.D., ${ }^{1}$ Young Baeg Kim, M.D., Ph.D., ${ }^{2}$ Seung Won Park, M.D., Ph.D., ${ }^{2}$ Dong Ho Kang, M.D., \\ Shin Heon Lee, M.D. ${ }^{2}$ \\ Department of Neurosurgery, Gyeongsang National University School of Medicine, Jinju, Korea \\ Department of Neurosurgery, ${ }^{2}$ Chung-Ang University College of Medicine, Seoul, Korea
}

Objective : The objective of this study was to analyze the correlation between further compression and necrotic area in osteoporotic vertebral fracture (OVF) patients with contrast-enhanced magnetic resonance imaging (CEMRI). In addition, we investigated the radiological and clinical outcome according to the range of the necrotic area.

Methods : Between 2012 and 2014, the study subjects were 82 OVF patients who did not undergo vertebroplasty or surgical treatment. The fracture areas examined on CEMRI at admission were defined as edematous if enhancement was seen and as necrotic if no enhancement was seen. The correlation between further compression and the necrotic and edematous areas of CEMRI, age, and bone mineral density was examined. Also, necrotic areas were classified into those with less than $25 \%$ (non-necrosis group) and those with more than $25 \%$ (necrosis group) according to the percentages of the entire vertebral body. For both groups, further compression and the changes in wedge and kyphotic angles were examined at admission and at 1 week, 3 months, and 6 months after admission, while the clinical outcomes were compared using the visual analog scale (VAS) and Eastern Cooperative Oncology Group (ECOG) performance status grade.

Results : Further compression was $14.78 \pm 11.11 \%$ at 1 month and $21.75 \pm 14.43 \%$ at 6 months. There was a very strong correlation between the necrotic lesion of CEMRI and further compression $(r=0.690, p<0.001)$. The compression of the necrosis group was $33.52 \pm 12.96 \%$, which was higher than that of the non-necrosis group, $14.96 \pm 10.34 \%(p<0.005)$. Also, there was a statistically significantly higher number of intervertebral cleft development and surgical treatments being performed in the necrosis group than in the non-necrosis group $(p<0.005)$. Moreover, there was a statistical difference in the decrease in the height of the vertebral body, and an increase was observed in the kyphotic change of wedge angle progression. There was also a difference in the VAS and ECOG performance scales.

Conclusion : The necrotic area of CEMRI in OVF had a strong correlation with further compression over time. In addition, with increasing necrosis, intervertebral clefts occurred more frequently, which induced kyphotic changes and resulted in poor clinical outcomes. Therefore, identifying necrotic areas by performing CEMRI on OVF patients would be helpful in determining their prognosis and treatment course.

Key Words : Osteoporotic vertebral fracture $\cdot$ Necrotic area $\cdot$ Further compression $\cdot$ Kyphotic change.

- Received : July 27, 2016 •Revised : October 19, 2016 •Accepted : November 17, 2016

- Address for reprints : Young-Seok Lee, M.D.

Department of Neurosurgery, Gyeongsang National University Hospital, 79 Gangnam-ro, Jinju 52727, Korea

Tel : +82-55-750-8112, Fax : +82-55-750-8737, E-mail : leeys1026@hanmail.net

This is an Open Access article distributed under the terms of the Creative Commons Attribution Non-Commercial License (http://creativecommons.org/licenses/by-nc/4.0) which permits unrestricted non-commercial use, distribution, and reproduction in any medium, provided the original work is properly cited. 


\section{INTRODUCTION}

Vertebroplasty or kyphoplasty is commonly used for the treatment of osteoporotic vertebral fracture $(\mathrm{OVF})^{6,17,18)}$. However, it was reported that there was either a similar or no beneficial effect of vertebroplasty in OVF compared to a control group in two prospective randomized multicenter trials in $2009^{1,7}$. However, many studies still report a superior effect of vertebroplasty in OVF, and thus there is still some debate about the therapeutic effect of vertebroplasty or kyphoplasty in OVF.

The most common complication of a conservative therapy in OVF is vertebral collapse caused by further compression over time ${ }^{2)}$. Particularly, OVF often develops in the thoracolumbar junction, in which stress-loading is greatest, and wedge-shaped fracture types primarily occur ${ }^{3}$. Thus, vertebral collapse induces progressive kyphosis and consequently persistent back pain and neurological deficiency.

We measured necrotic and edematous area using highly reliable and sensitive contrast-enhanced magnetic resonance imaging (CEMRI) in OVF and examined the strength of the correlation by comparing with compression after 6 months. Additionally, comparative analysis was performed to determine how the range of the necrotic area affected not only radiological outcome but also clinical outcome.

\section{MATERIALS AND METHODS}

\section{Subjects}

Eighty-seven patients admitted for OVF from January 2012 to December 2014 were retrospectively recruited as study subjects. The OVF patients engaged in this study were patients aged 50 and older who had single-level vertebral fracture without posterior ligament injury among $\mathrm{AO}$ classification A1-3 and compression or burst fracture without neurological deficiency; all subjects also had adequate pain relief with a score of 1-2 points in the thoracolumbar injury classification and severity score ${ }^{15,16}$. Adequate pain relief was based on a visual analog scale (VAS) (0-10) score maintained below 5 points with an active medical therapy (opioid medication and pain block). During this period, vertebroplasty or kyphoplasty was performed in five patients (5.7\%). Of these, five patients were $\mathrm{AO}$ classification $\mathrm{A} 3$ and complained of intolerable pain for 1 month or longer. This study was conducted without external funding.

\section{Compression}

Further compression was measured by means of lateral plain radiography. The ratio (\%) of reduced vertebral body area was measured at 1 month and 6 months based on the vertebral body area of fracture on lateral plain radiography at admission. Additionally, the edematous and necrotic areas of the fracture lesion in a middle sagittal section were measured using CEMRI, and the fracture areas examined on CEMRI at admission were defined as edematous if enhancement was seen and as necrotic if no enhancement was seen using picture archiving and communication system (Maroview version 5.4, Marotech Inc., Seoul, Korea). The areas of necrosis, edema, and necrosis+edema were obtained as a ratio (\%) based on the entire area of the fractured vertebral body (Fig. 1A) ${ }^{12}$. Then, correlations of further compression were studied with respect to the necrotic and edematous areas seen on CEMRI, age, and bone mineral density (BMD), which were believed to be closely correlated with further compression.

Based on this, comparative analysis of the clinical and radiological outcome of each group was performed by dividing the groups into those with necrotic areas of less than $25 \%$ (non-necrosis group) or more than 25\% group (necrosis group) based on the size of the necrotic area on CEMRI.

\section{Outcome measures}

For clinical outcomes, VAS and Eastern Cooperative Oncology Group (ECOG) performance status were used at 1 month, 3 months, and 6 months after admission to verify the severity and duration of pain ${ }^{11)}$. In accordance with the ECOG performance status grade, grade 0 indicates fully active, able to carry on all pre-disease performance without restriction; grade 1 indicates symptomatic but fully ambulatory; Grade 2 indicates symptomatic and up and about for more than 50\% of waking hours; and Grade 3 indicates symptomatic and confined to bed or a chair for $50 \%$ of waking hours.

The development of the intervertebral cleft was defined as cases in which intervertebral air or fluid was observed or change in anterior vertebral height of $\geq 3 \mathrm{~mm}$ was observed on flexion/extension lateral plain radiography.

Anterior, middle, and posterior height were measured on lateral plain radiography at admission and at 1 week, 1 month, 

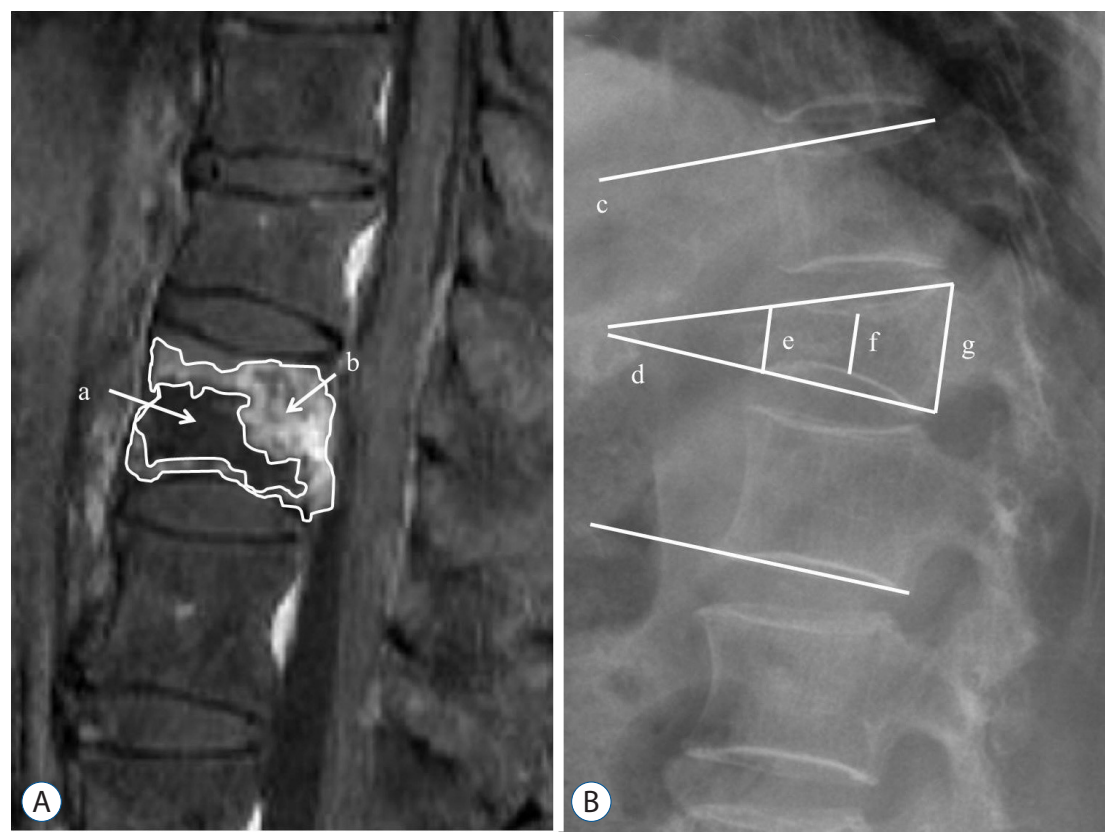

Fig. 1. A : Contrast-enhanced magnetic resonance image shows necrotic (a) and edematous (b) areas. B : Radiography shows the segmental angle (c), wedge angle (d), anterior height (e), middle height (f), and posterior height $(\mathrm{g})$ in osteoporotic vertebral fracture.

and 6 months after admission; the Cobb angle comprised of the upper endplate and the lower endplate of the fractured vertebral body was defined as the wedge angle, and the Cobb angle comprised of the upper endplate of the upper vertebral body and the lower endplate of the lower vertebral body of a fractured vertebral body was defined as the segmental angle (Fig. 1B).

\section{Statistical analysis}

The Pearson method was used to determine the correlation between further compression and necrosis and edema, BMD, and age on contrast-enhanced MRI. Variables between the non-necrosis and necrosis groups were compared using an independent t-test, Mann-Whitney's U test, and chi-squared test. $p<0.05$ was considered statistically significant. Statistical analyses were performed using SPSS software version 18.0 (SPSS Inc., Chicago, IL, USA).

\section{RESULTS}

The study was performed in a total of 82 patients from January 2012 to December 2014, the mean age of subjects was $69.27 \pm 10.33$ years, and the ratio of men to women was 18 to 64 , indicating a greater number of women. Distribution was mainly in T12, L1, and L2. When the entire fractured area on plain radiography examined at admission was set as a baseline, the development of further compression was $14.78 \pm 11.11 \%$ at 1 month post-injury and $21.75 \pm 14.43 \%$ at 6 months post-injury. Moreover, on the CEMRI, the necrotic area accounted for $21.71 \pm 16.27 \%$, the edematous area accounted for $47.93 \pm 16.54 \%$, and the fractured area accounted for $69.64 \pm 19.12 \%$ (Table 1). According to this, the correlation between the degree of further compression at 6 months post-injury and age, BMD, necrotic area, and edematous area was obtained. There was no correlation between further compression and age and BMD, but there was a positive correlation between further compression and necrotic area (Pearson's correlation coefficient $=0.690$, $p<0.001$; Fig. 2). The further compression that developed at 6 months post-injury was almost identical to the necrotic area on contrast-enhanced MRI.

Comparative analysis was performed by dividing the subjects into non-necrosis and necrosis groups based on the size of the necrotic area on CEMRI. There was no difference between the two groups in terms of age, sex, hypertension, diabetes mellitus, BMD, vertebral shape, and osteoporotic medication. However, when compression was measured at 1 month and 6 months, it was $10.35 \pm 7.09$ and $14.96 \pm 10.34 \%$ in the non-necrosis group, respectively, but was statistically significantly higher $22.46 \pm 12.64$ and $33.52 \pm 12.96 \%$ at the necrosis group, respectively (Fig. 3). Moreover, the development of intervertebral cleft $(n=13,43.3 \%)$ in the necrosis group 
was higher than that $(n=6,11.5 \%)$ in the non-necrosis group; furthermore, three patients in the necrosis group needed surgical treatment due to neurologic deficiency. The necrosis group had a statistically significantly poorer clinical outcome in comparison to the non-necrosis group based on VAS at 1 month, 3 months, and 6 months post-injury. Moreover, ECOG performance status showed similar results (Table 2).

In regards to radiologic outcome, vertebral height and wedge and segmental angles at 1 week, 1 month, and 6 months after injury were compared. As a result, statistical differences

Table 1. Patient demographic data

\begin{tabular}{|c|c|}
\hline Variable & Value \\
\hline Age & $69.27 \pm 10.33$ \\
\hline $\operatorname{Sex}(M: F)$ & $18: 64$ \\
\hline Hypertension & 38 \\
\hline DM & 16 \\
\hline Smoking & 9 \\
\hline \multicolumn{2}{|l|}{ Level } \\
\hline T11 & 2 \\
\hline $\mathrm{T} 12$ & 19 \\
\hline L1 & 31 \\
\hline L2 & 26 \\
\hline L3 & 4 \\
\hline \multicolumn{2}{|l|}{ Vertebral shape } \\
\hline Wedge & 51 \\
\hline Biconcave & 17 \\
\hline Crush & 14 \\
\hline BMD & $-2.74 \pm 1.22$ \\
\hline Further compression rate at 1 month (\%) & $14.78 \pm 11.11$ \\
\hline Further compression rate at 6 month (\%) & $21.75 \pm 14.43$ \\
\hline Necrosis area (\%) & $21.71 \pm 16.27$ \\
\hline Edema area (\%) & $47.93 \pm 16.54$ \\
\hline Necrosis+Edema area (\%) & $69.64 \pm 19.12$ \\
\hline Unhealed & 19 \\
\hline Surgery & 3 \\
\hline VAS (1 month) & $2.99 \pm 0.83$ \\
\hline VAS (3 months) & $2.37 \pm 1.18$ \\
\hline VAS (6 months) & $2.28 \pm 1.15$ \\
\hline ECOG performance scale (0/1/2/3) & $42 / 28 / 10 / 2$ \\
\hline
\end{tabular}

Values are presented as mean \pm standard deviation or number. DM : diabetes mellitus, BMD : bone mineral density, VAS : visual analog scale, ECOG : Eastern Cooperative Oncology Group in anterior vertebral height were seen starting from 1 week after injury. In addition, over time, there was a difference between the two groups in middle and posterior vertebral height. Moreover, wedge and segmental angles showed a dif-

Table 2. Clinical data of patients

\begin{tabular}{lcr}
\hline Variable & $\begin{array}{c}\text { Necrosis }<\mathbf{2 5 \%} \\
(\mathbf{n}=\mathbf{5 2})\end{array}$ & $\begin{array}{r}\text { Necrosi } \\
(\mathbf{n}=30)\end{array}$ \\
\hline Age (year) & $68.69 \pm 11.97$ & 70.27 \\
Sex (M : F) & $11: 41$ & $7: 23$ \\
Hypertension & 25 & \\
DM & 11 & \\
Smoking & 6 & 13 \\
Level & & \\
T11 & 1 & \\
T12 & 7 & \\
L1 & 21 & \\
L2 & 22 & \\
L3 & 1 &
\end{tabular}

$\begin{array}{lrr}\text { Vertebral shape } & \\ \text { Wedge } & 36 & 15 \\ \text { Biconcave } & 9 & 8 \\ \text { Crush } & 7 & 7\end{array}$

\begin{tabular}{|c|c|c|c|}
\hline Osteoporotic medication & & & 0.765 \\
\hline Bisphosphonate & 24 & 15 & \\
\hline Teriparatide & 12 & 8 & \\
\hline BMD & $-2.69 \pm 1.31$ & $-2.87 \pm 1.05$ & 0.625 \\
\hline $\begin{array}{l}\text { Further compression at } \\
1 \text { month (\%)* }\end{array}$ & $10.35 \pm 7.09$ & $22.46 \pm 12.64$ & $<0.001$ \\
\hline $\begin{array}{l}\text { Further compression at } \\
6 \text { months (\%)* }\end{array}$ & $14.96 \pm 10.34$ & $33.52 \pm 12.96$ & $<0.001$ \\
\hline Necrotic area $(\%)^{*}$ & $11.95 \pm 7.35$ & $38.62 \pm 13.33$ & $<0.001$ \\
\hline Edematous area (\%) & $50.23 \pm 17.94$ & $43.59 \pm 13.22$ & 0.098 \\
\hline $\begin{array}{l}\text { Necrotic+Edematous } \\
\text { area }(\%)^{*}\end{array}$ & $62.18 \pm 17.95$ & $82.57 \pm 13.48$ & $<0.001$ \\
\hline Intervertebral cleft* & 6 & 13 & 0.002 \\
\hline Surgery* & 0 & 3 & 0.046 \\
\hline VAS (1 month)* & $2.74 \pm 0.83$ & $3.77 \pm 1.01$ & $<0.001$ \\
\hline VAS (3 months)* & $1.87 \pm 0.91$ & $3.23 \pm 1.10$ & $<0.001$ \\
\hline VAS (6 months)* & $1.79 \pm 0.82$ & $3.13 \pm 1.14$ & $<0.001$ \\
\hline $\begin{array}{l}\text { ECOG performance } \\
\text { scale }(0 / 1 / 2 / 3)^{*}\end{array}$ & $33 / 16 / 3 / 0$ & $9 / 12 / 7 / 2$ & 0.001 \\
\hline
\end{tabular}

Values are presented as mean \pm standard deviation or number. *Statistically significant difference. DM : diabetes mellitus, BMD : bone mineral density, VAS : visual analog scale, ECOG : Eastern Cooperative Oncology Group 

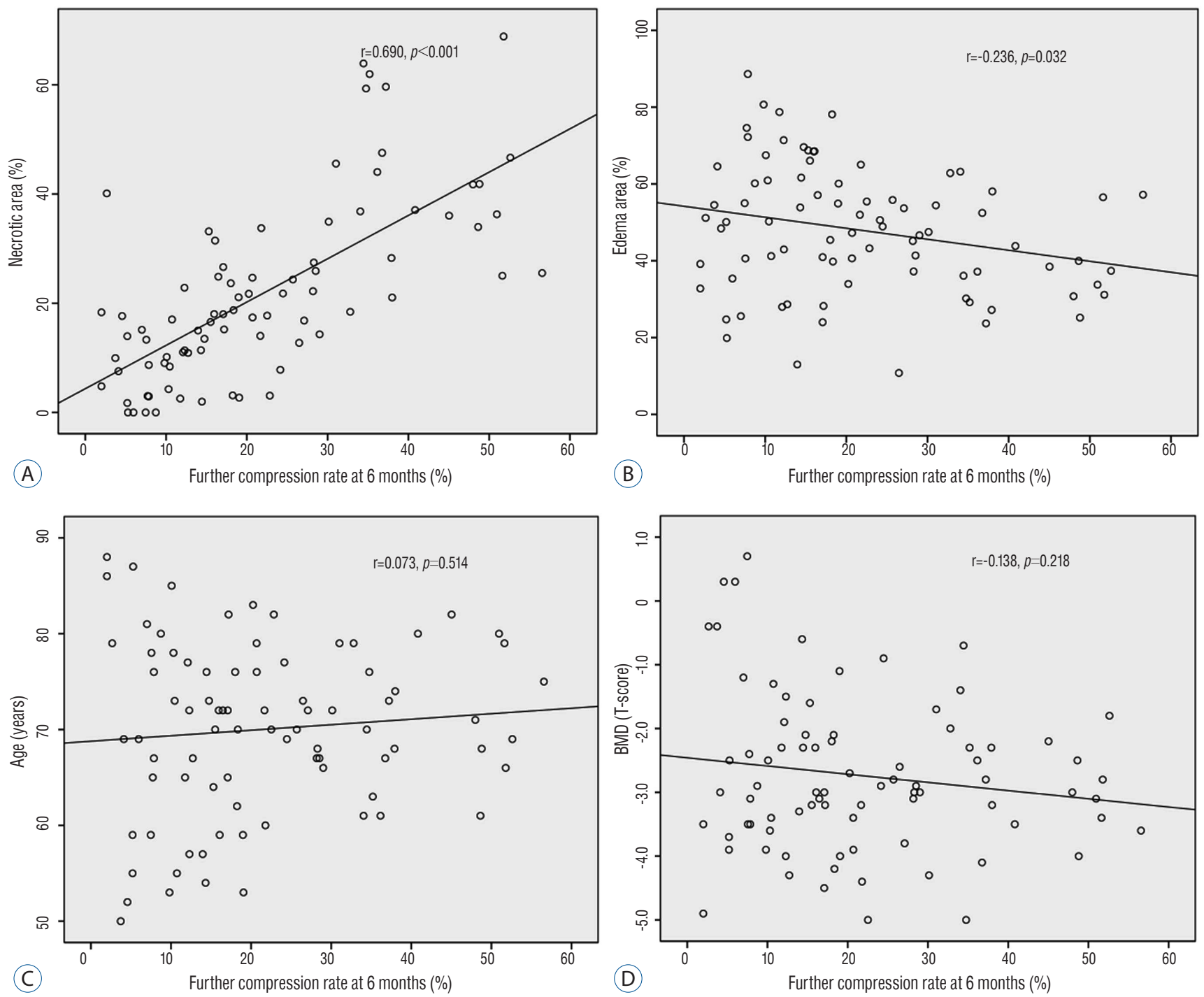

Fig. 2. Correlations of further compression at 6 months and factors affecting further compression. The $x$ axes indicate further compression at 6 months. The y axes indicate (A) necrotic area (\%) on contrast-enhanced MRI, (B) edema area (\%) on contrast-enhanced MRI, (C) age, and (D) BMD. Further compression at 6 months and necrotic area (\%) shows the strongest correlation. MRI : magnetic resonance imaging, BMD : bone mineral density, $r$ : correlation coefficient.

ference at 6 months post-injury, and the difference between the two groups increased for both wedge and segmental angle over time (Table 3).

\section{DISCUSSION}

Vertebral collapse often occurs unpredictably in OVF and develops as a consequence of a vascular insult in the anterior segment of the vertebral body supplied by the anterior me- taphyseal and peripheral arteries. This induces inadequate revascularization in bone marrow and impairs the fracture healing process, thus it induces failure of the reparative process and promotes avascular necrosis of the vertebral body. Consequently, vertebral collapse develops progressively ${ }^{12,14)}$. The current result also shows that the incidence of further compression was $14.8 \%$ at 1 month and $21.8 \%$ at 6 months when conservative therapy was attempted in OVF.

CEMRI is a highly reliable and sensitive test that can accurately verify the range of avascular necrosis in OVF patients ${ }^{12}$. 

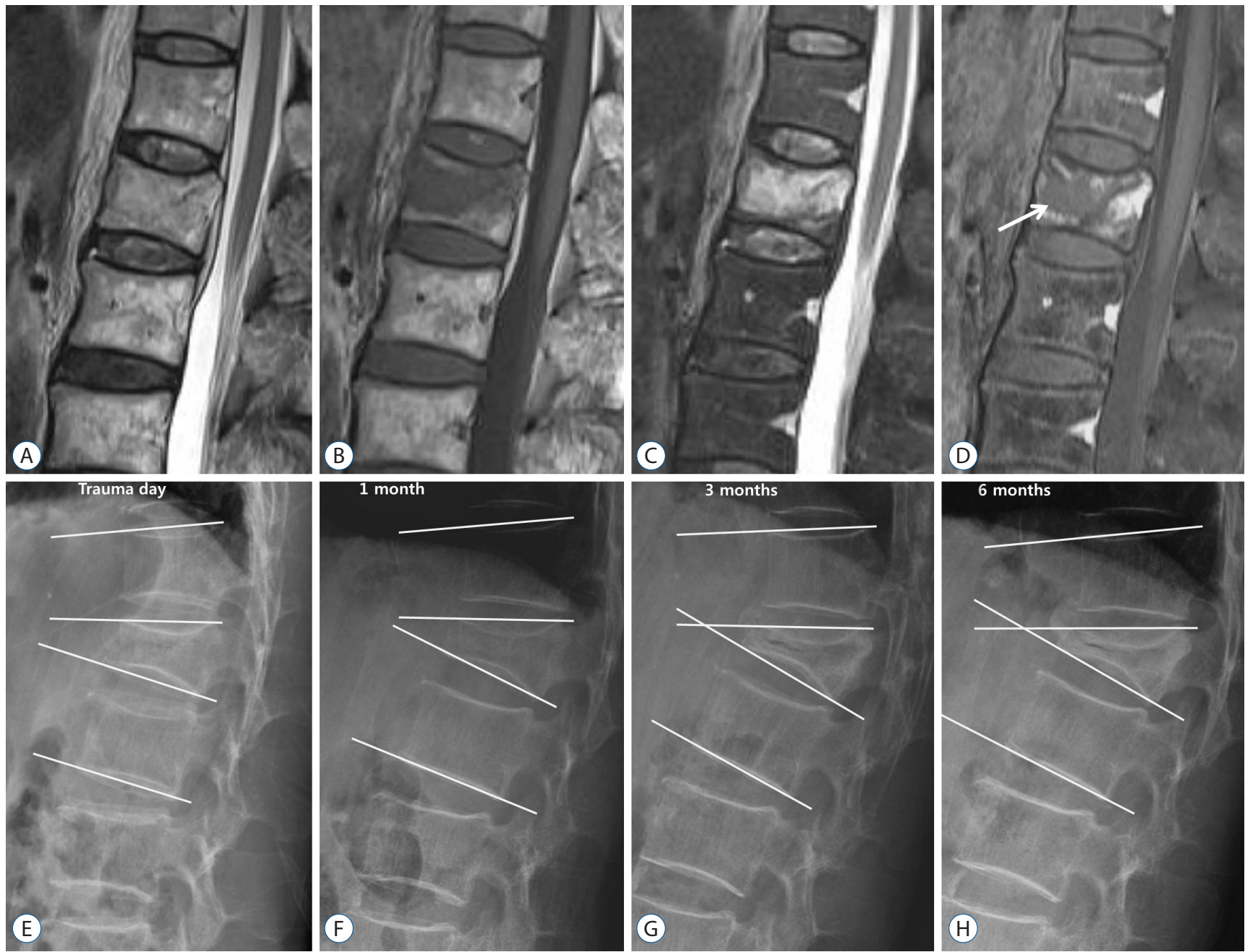

Fig. 3. A 76-year-old man with a benign osteoporotic vertebral fracture of the first lumbar vertebra. On (A) T2-, (B) T1-, and (C) fat-suppressed T2weighted MRI, the signal of the vertebral body appears as isointensity and low and high signal intensity rather than as signal void. On (D) contrastenhanced MRI, an area (arrow) with low signal intensity (necrotic area) is clearly shown within a diffusely enhanced area (edematous area). (E-G), and (H) on plain lateral radiography, there was a gradual reduction of disc height, and the conversion of wedge and segmental angles into a kyphotic change was found over time. MRI : magnetic resonance imaging.

Moreover, the enhancing pattern of a fractured vertebra on CEMRI is useful to assess blood supply in bone contusions. Additionally, the ischemic necrotic area on CEMRI can be used to predict the pattern and amount of injected bone cement when percutaneous vertebroplasty was performed ${ }^{11}$. The present study also showed further compression developed in proportion to the necrotic portion on CEMRI in OVF. This indicates that the degree of further compression is readily predictable through CEMRI, and thus it would be helpful for selecting patients requiring vertebroplasty, kyphoplasty, or surgery.

Comparisons between the two groups were made based on the range of necrosis. Consequently, the incidence of intervertebral cleft and cases requiring a surgical procedure were greater in the necrosis group. Accordingly, it was demonstrated that intervertebral cleft occurred more frequently in cases with a large range of necrosis. Intervertebral cleft increases mobility and induces more pain per $\mathrm{se}^{6,8,9)}$. Likewise, it has been reported that the incidence of cement leakage is high when vertebroplasty is performed in cases of intervertebral cleft, and the benefit of vertebroplasty is a delayed and decreased effect ${ }^{4,8}$. Because cement is injected in a clump-like pattern in a condition with intervertebral cleft rather than in a sponge-like pattern in a condition without intervertebral 
Table 3. Radiologic changes over time

\begin{tabular}{|c|c|c|c|c|c|}
\hline & & Trauma day & 1 week & 1 month & 6 months \\
\hline \multirow[t]{2}{*}{ Anterior height (mm) } & Necrosis $<25 \%$ & $20.46 \pm 4.80$ & $19.23 \pm 4.68$ & $17.82 \pm 4.41$ & $16.30 \pm 4.51$ \\
\hline & Necrosis $>25 \%$ & $19.42 \pm 4.44$ & $16.58 \pm 4.32$ & $13.66 \pm 3.91$ & $11.21 \pm 3.33$ \\
\hline$p$-value & & 0.334 & $0.013^{*}$ & $<0.001^{*}$ & $<0.001^{*}$ \\
\hline \multirow[t]{2}{*}{ Middle height (mm) } & Necrosis $<25 \%$ & $17.22 \pm 4.36$ & $15.46 \pm 4.67$ & $14.85 \pm 3.97$ & $13.06 \pm 4.05$ \\
\hline & Necrosis $>25 \%$ & $16.18 \pm 3.76$ & $13.94 \pm 3.42$ & $11.99 \pm 3.19$ & $10.19 \pm 3.15$ \\
\hline$p$-value & & 0.277 & 0.124 & $0.001^{*}$ & $0.001^{*}$ \\
\hline \multirow[t]{2}{*}{ Posterior height (mm) } & Necrosis $<25 \%$ & $27.65 \pm 4.98$ & $26.67 \pm 4.68$ & $25.98 \pm 5.87$ & $25.47 \pm 4.96$ \\
\hline & Necrosis $>25 \%$ & $26.04 \pm 4.10$ & $24.94 \pm 3.41$ & $24.26 \pm 3.97$ & $22.18 \pm 4.63$ \\
\hline$p$-value & & 0.137 & 0.081 & 0.158 & $0.004^{*}$ \\
\hline \multirow[t]{2}{*}{ Wedge angle $\left({ }^{\circ}\right)$} & Necrosis $<25 \%$ & $11.68 \pm 6.48$ & $13.57 \pm 5.86$ & $15.51 \pm 6.69$ & $15.90 \pm 6.71$ \\
\hline & Necrosis $>25 \%$ & $10.87 \pm 5.79$ & $14.22 \pm 6.03$ & $18.05 \pm 5.18$ & $19.30 \pm 7.48$ \\
\hline$p$-value & & 0.572 & 0.637 & 0.078 & $0.037^{*}$ \\
\hline \multirow[t]{2}{*}{ Segmental angle $\left(^{\circ}\right)$} & Necrosis $<25 \%$ & $9.96 \pm 8.77$ & $10.63 \pm 9.80$ & $12.37 \pm 9.97$ & $14.06 \pm 9.86$ \\
\hline & Necrosis $>25 \%$ & $8.93 \pm 6.99$ & $12.22 \pm 8.09$ & $15.70 \pm 8.95$ & $18.85 \pm 9.75$ \\
\hline$p$-value & & 0.587 & 0.452 & 0.134 & $0.037^{*}$ \\
\hline
\end{tabular}

Values are presented as mean \pm standard deviation. *Statistically significant difference

cleft when vertebroplasty was performed, the interdigitation of bone and cement becomes weakened. Thus, interlocking bone is weakened, the stabilizing effect of cement is reduced, and consequently the pain reduction effect is small ${ }^{10)}$. Furthermore, a surgical procedure can be necessary as nonunion develops. In our results, the incidence of intervertebral cleft was $43.3 \%$ in the necrosis group. In addition, the possibility of intervertebral cleft development is high if the necrotic range is large on CEMRI. his may serve as a sufficiently useful indicator to select patients who might benefit from active treatment after assessment of the necrotic range.

The kyphotic change in OVF aggravates physical function and quality of life ${ }^{13)}$. Vertebral kyphotic deformity also increases mortality and adjacent fracture incidence ${ }^{5}$. The radiological outcome in our results showed a difference between the two groups. OVF develops most commonly in wedgeshaped fractures, and the necrotic portion is mainly located anteriorly, and thus the vertebral height decreases from the anterior vertebral height in order. Furthermore, it was found that the wedge and kyphotic angles worsened in the group whose necrosis advanced over time. This was a major cause of constant back pain and affected performance status.
This study has some limitations. This study used retrospective data at a single medical center. To overcome this limitation, medical treatment and pain block was actively performed, and vertebroplasty or kyphoplasty was performed in only $5.7 \%$ of OVF patients. In addition, plain radiography was consistently measured, and the progress was observed to 6 months, which is sufficient to determine if neurologic deficiency had developed. However, the short-term 6-month follow-up is a limitation. Accordingly, a long-term multicenter prospective study is needed in further studies.

\section{CONCLUSION}

There is a strong correlation between the necrotic area on CEMRI and the development of further compression in OVF. Additionally, with a large degree of necrosis, intervertebral cleft develops, and kyphotic change is induced with poor clinical outcome. Therefore, identifying necrotic areas by performing CEMIRI on OVF patients would be helpful in determining their prognosis and treatment course. 


\section{References}

1. Buchbinder R, Osborne RH, Ebeling PR, Wark JD, Mitchell P, Wriedt C, et al. : A randomized trial of vertebroplasty for painful osteoporotic vertebral fractures. N Engl J Med 361 : 557-568, 2009

2. Carlier RY, Gordji H, Mompoint DM, Vernhet N, Feydy A, Vallee C : Osteoporotic vertebral collapse : percutaneous vertebroplasty and loca kyphosis correction. Radiology 233 : 891-898, 2004

3. Chou KN, Lin BJ, Wu YC, Liu MY, Hueng DY : Progressive kyphosis after vertebroplasty in osteoporotic vertebral compression fracture. Spine (Phila Pa 1976) 39 : 68-73, 2014

4. Ha KY, Lee JS, Kim KW, Chon JS : Percutaneous vertebroplasty for vertebral compression fractures with and without intravertebral clefts. $J$ Bone Joint Surg Br 88 : 629-633, 2006

5. Hasserius R, Karlsson MK, Nilsson BE, Redlund-Johnell I, Johnell O; European Vertebral Osteoporosis Study : Prevalent vertebral deformities predict increased mortality and increased fracture rate in both men and women : a 10-year population-based study of 598 individuals from the Swedish cohort in the European Vertebral Osteoporosis Study. Osteoporos Int $14: 61-68,2003$

6. Jang JS, Kim DY, Lee SH : Efficacy of percutaneous vertebroplasty in the treatment of intravertebral pseudarthrosis associated with noninfected avascular necrosis of the vertebral body. Spine (Phila Pa 1976) 28 : 1588-1592, 2003

7. Kallmes DF, Comstock BA, Heagerty PJ, Turner JA, Wilson DJ, Diamond $\mathrm{TH}$, et al. : A randomized trial of vertebroplasty for osteoporotic spinal fractures. N Engl J Med 361 : 569-579, 2009

8. Kim DY, Lee SH, Jang JS, Chung SK, Lee HY : Intravertebral vacuum phenomenon in osteoporotic compression fracture : report of 67 cases with quantitative evaluation of intravertebral instability. J Neurosurg 100(1 Suppl Spine) : 24-31, 2004

9. McKiernan F, Jensen $R$, Faciszewski $T$ : The dynamic mobility of vertebral compression fractures. J Bone Miner Res 18 : 24-29, 2003

10. Nieuwenhuijse MJ, van Rijswijk CS, van Erkel AR, Dijkstra SP : The intravertebral cleft in painful long-standing osteoporotic vertebral compression fractures treated with percutaneous vertebroplasty : diagnostic assessment and clinical significance. Spine (Phila Pa 1976) 37 : 974981, 2012

11. Oka M, Matsusako M, Kobayashi N, Uemura A, Numaguchi Y : Intravertebral cleft sign on fat-suppressed contrast-enhanced MR : correlation with cement distribution pattern on percutaneous vertebroplasty. Acad Radiol 12 : 992-999, 2005

12. Ryu CW, Han H, Lee YM, Lim MK : The intravertebral cleft in benign vertebral compression fracture : the diagnostic performance of nonenhanced MRI and fat-suppressed contrast-enhanced MRI. Br J Radiol 82 : 976-981, 2009

13. Silverman SL, Minshall ME, Shen W, Harper KD, Xie S; Health-Related Quality of Life Subgroup of the Multiple Outcomes of Raloxifene Evaluation Study : The relationship of health-related quality of life to prevalent and incident vertebral fractures in postmenopausal women with osteoporosis : results from the Multiple Outcomes of Raloxifene Evaluation Study. Arthritis Rheum 44 : 2611-2619, 2001

14. Theodorou DJ : The intravertebral vacuum cleft sign. Radiology 221 : 787-788, 2001

15. Vaccaro AR, Oner C, Kepler CK, Dvorak M, Schnake K, Bellabarba C, et al. : AOSpine thoracolumbar spine injury classification system : fracture description, neurological status, and key modifiers. Spine (Phila Pa 1976) 38 : 2028-2037, 2013

16. Vaccaro AR, Lehman RA Jr, Hurlbert RJ, Anderson PA, Harris M, Hedlund $R$, et al. : A new classification of thoracolumbar injuries : the importance of injury morphology, the integrity of the posterior ligamentous complex, and neurologic status. Spine (Phila Pa 1976) 30 : 2325-2333, 2005

17. Wang $\mathrm{G}$, Yang $\mathrm{H}$, Chen $\mathrm{K}$ : Osteoporotic vertebral compression fractures with an intravertebral cleft treated by percutaneous balloon kyphoplasty. J Bone Joint Surg Br 92 : 1553-1557, 2010

18. Wang H, Sribastav SS, Ye F, Yang C, Wang J, Liu H, et al. : Comparison of percutaneous vertebroplasty and balloon kyphoplasty for the treatment of single level vertebral compression fractures : a meta-analysis of the literature. Pain Physician 18 : 209-222, 2015 